\title{
IRON NUTRITION OF PHYTOPLANKTON AND ITS POSSIBLE IMPORTANCE IN THE ECOLOGY OF OCEAN REGIONS WITH HIGH NUTRIENT AND LOW BIOMASS
}

By François M.M. Morel, John G. Rueter and Neil M. Price

I SOME REGIONS of the oceans, namely the North and Equatorial Pacific and the Antarctic, the surface waters contain relatively high concentrations of nutrients (e.g., $\mathrm{PO}_{4}>1 \mu \mathrm{M}$ ) yet only a low biomass (chlorophyll $<0.5 \mu \mathrm{g} / \mathrm{L}$ ). On the basis of measurements of very low iron concentrations $(<0.1 \mathrm{nM})$ and observations of increased growth on Fe enrichments, J. Martin and coworkers have proposed that iron limits primary production in these waters (Martin, 1991, this issue). Other authors have proposed alternate hypotheses chiefly on the basis of grazing (Miller $e t$ al., 1991, this issue) and light limitation (Mitchell et al., 1991). Here we examine the "iron hypothesis" in light of what we know about the iron physiology of marine phytoplankton and its relation to iron chemistry.

the most versatile and

important trace

element for

biochemical catalysis.

\section{Iron Requirements}

The oxidation-reduction properties of iron make it ideally suited to catalyze electron transfer reactions. In the course of evolution (the early part of which occurred in an anoxic and thus Ferich environment), microorganisms have exploited iron for photosynthetic and respiratory functions as well as for the reduction of inorganic nitrogen species, nitrate, nitrite, and nitrogen gas (dinitrogen). Iron is undoubtedly the most versatile and important trace element for biochemical catalysis. Because of variations in its molecular surroundings, the redox potential of iron in heme proteins such as cytochromes and in iron-sulfur proteins such as ferredoxin (one of the most reduced cellular compounds produced in photosynthesis) can span as much as 1 volt, practically the whole range from inorganic carbon to sugars (Morel, 1983).

F.M.M. Morel and N.M. Price, R.M. Parsons Laboratory, Massachusetts Institute of Technology, Cambridge, MA, 02139 , USA. J.G. Rueter, Department of Biology, Portland State University, P.O. Box 751, Portland. OR, 97207. USA.
On the basis of the known turnover times and compositions of iron-containing redox proteins. one can calculate the minimum iron necessary for an organism to grow at a given rate (Raven. 1988). For a typical marine alga dividing once a day, the calculated minimum iron requirements are roughly $10 \mu \mathrm{mol} \mathrm{Fe} / \mathrm{mol} \mathrm{C}$ for photosynthesis and respiration. If the alga is grown on nitrate rather than ammonium, this requirement is increased to roughly $15 \mu \mathrm{mol} \mathrm{Fe} / \mathrm{mol} \mathrm{C}$. Nitrogen fixation in cyanobacteria (alias blue-green algae) is even more iron expensive, requiring probably $>200 \mu \mathrm{mol} \mathrm{Fe} / \mathrm{mol} \mathrm{C}$.

Iron-containing molecules can be replaced in some of their functions by other molecules, however. For example, the copper protein plastocyanin and cytochrome c-552 can fulfill similar functions and replace each other in some organisms (Wood, 1978). Flavodoxin, a nonmetal redox compound, can substitute for ferredoxin in certain reactions in blue-green and green algae and possibly in others as well (Zumft and Spiller, 1971). Perhaps manganese or vanadium enzymes can replace particular iron enzymes in some phytoplankton. Undoubtedly, much is yet to be learned regarding possible iron substitutions. Although it is probably safe to consider iron an essential nutrient for free-living organisms, minimum Fe requirements may not be easily calculated.

\section{The Iron Uptake System}

Some one billion years ago, blue-green algae had evolved sufficient oxygen to completely change the conditions of the earth environmentfrom anoxic to oxic. Aside from the direct noxious effect of oxygen and its derivatives, one dramatic side effect of this change was the practical elimination of iron from the aquatic environment because oxidized $\mathrm{Fe}$ (III) is extremely insoluble at neutral $\mathrm{pH}$. To solve this problem, terrestrial bacteria have evolved the capability to synthesize specific iron-complexing agents, low-molecular- 
weight compounds called siderophores, and release them in their external milieu. After reaction with the rare iron molecules in the medium, the iron-siderophore complex is taken up by the cells via specific carrier proteins imbedded in their membranes (Neilands, 1981). Oceanic bacteria, including the photosynthetic cyanobacteria, may also produce siderophores, though they may not be released to the surrounding water (Reid and Butler, 1991). There is yet no evidence of siderophores in solution in seawater, and some of the marine bacterial siderophores appear to be membrane-bound. This of course would make sense in such dilute environs as the oceans. Some ongoing work is elucidating the types of siderophores found in marine bacteria, but no study of the kinetics of bacterial iron uptake has been made.

Our knowledge of the iron uptake system in eukaryotic marine phytoplankton is opposite to that of bacteria; we know the uptake kinetics in detail but we do not know the exact nature of the molecules involved. We know that the uptake molecules are normally membrane-bound and of small molecular weight. In at least one study involving batch cultures of large dinoflagellates, these molecules were released to the medium at the end of the exponential growth phase and turned out to be siderophores (Trick et al., 1983).
Thus, marine algae may be taking up iron through membrane-bound siderophores. In any case, iron uptake in marine phytoplankton involves a complexation reaction between iron in the water and an uptake molecule at the cell surface, followed by internalization of the membrane-bound iron (Hudson and Morel, 1990). The result is a hyperbolic rate law for uptake, increasing linearly with the iron in solution until the uptake sites are saturated and the transport rate maximized (Fig. 1).

\section{What Forms of Iron are Taken Up?}

Oceanic iron, recycled from deep water, advected from continental input, or originating from aeolian dust, occurs only partly in the dissolved form. Between 10 and 50\% passes through 0.4$\mu \mathrm{m}$ filters (Martin and Gordon, 1988; Martin $e t$ al., 1989), and some of this may be colloidal rather than truly dissolved. The particulate and colloidal fraction comprises oxides and aluminosilicates and possibly organic forms. Some of the dissolved fraction also may be organically bound and some (probably very little) may be in the reduced Fe(II) form rather than the stable $\mathrm{Fe}(\mathrm{III})$ in oxygenated water. The subject of Fe speciation in seawater is yet an unresolved analytical challenge.

From culture studies it appears that only the
... iron uptake in

marine phytoplankton

involves a

complexation reaction

between iron in the

water and an uptake

molecule at the cell

surface ...

HIGH Fe

$\mathrm{Fe}(\mathrm{OH})_{2}\left(\mathrm{H}_{2} \mathrm{O}\right)_{4}^{+}$

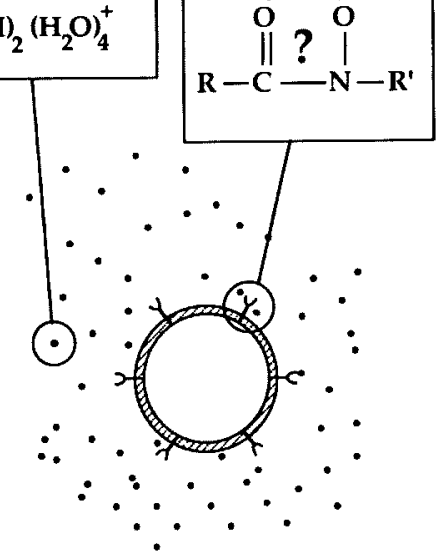

Lower Fe

More uptake molecules
Michaelis-Menten Uptake Kinetics

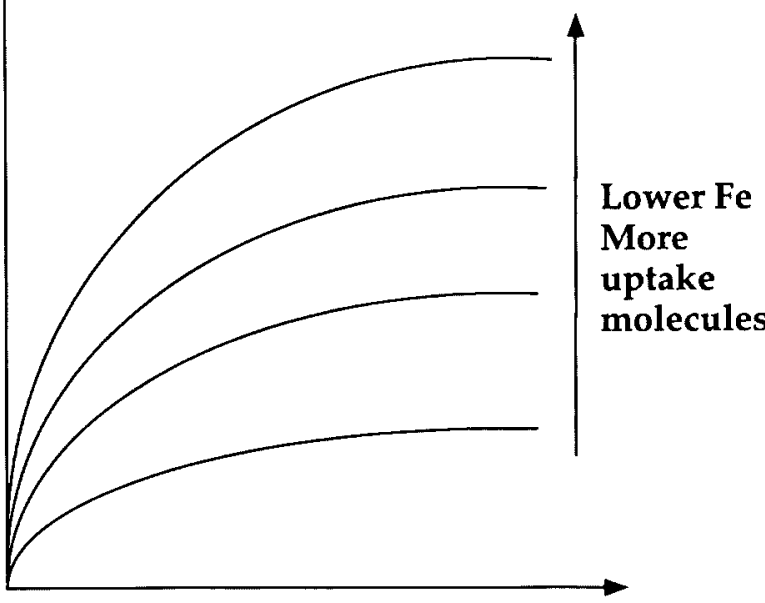

[Fe]

Fig. 1: Schematic representation of phytoplankton and their cell-surface Fe-transport ligands in seawater containing high and low concentrations of dissolved Fe. The Fe-transport ligands are hypothesized to resemble hydroxamate siderophores ( $R$-CO-NOH-R'). Increased Fe-transport ligand density in phytoplankton grown in low-Fe seawater increases the maximum rate of $\mathrm{Fe}$ uptake by the cells. 
... illumination of

iron (III)-oxide

suspensions makes

them more available to

phytoplankton. dissolved inorganic forms of iron, chiefly the dominant hydrolysis species $\mathrm{Fe}(\mathrm{OH})_{2}^{+}$, are taken up by marine phytoplankton. Although older work claimed that colloidal Fe might be a usable source of iron for algae (Goldberg, 1952), this does not appear to be the case. All colloids rigorously tested, including some that are only $2 \mathrm{~nm}$ in diameter and contain merely six Fe atoms, require prior dissolution to support algal growth (Rich and Morel, 1990). This result, of course, makes sense when one views the uptake process as dependent on a chemical reaction of iron with uptake sites. Strong coordination of Fe to ligands in solid or dissolved compounds should effectively hinder this necessary chemical reaction. It also makes sense from an evolutionary point of view because the low diffusion rate of colloids would make it a negligible advantage to utilize them as an iron source. The diffusion-limited uptake rate (see below) of a 50-nm colloid would be a hundred times less than that of a $0.5-\mathrm{nm}$ molecule, whereas the concentration would only increase a few fold at the most. Uptake of colloidal iron may occur in some phagocytotic algae (i.e., those that ingest whole particles) but is unlikely to represent an important pathway in oceanic waters. This does not rule out the interesting possibility that some algae such as Trichodesmium may grow as colonies attached to iron-rich particles.

The necessity for the iron to be in dissolved inorganic form in order to be available to algae underscores the importance of iron chemistry in surface seawater, about which little is known. Besides coordination reactions, the photochemistry of $\mathrm{Fe}$ in dissolved and particulate forms may be important (Fig. 2). It has been shown that illumination of iron(III)-oxide suspensions makes

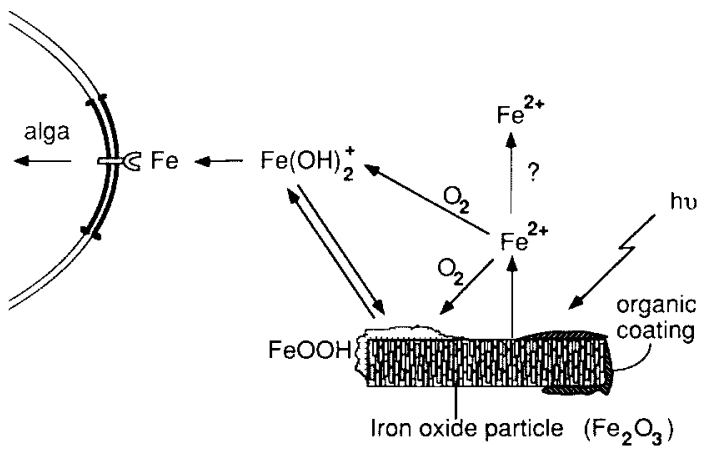

Fig. 2: Redox cycle of Fe in seawater in the presence of $e^{-}$donors such as organic compounds. Iron oxides $\left(\mathrm{Fe}_{2} \mathrm{O}_{3}\right)$ are photoreduced (hv) and release $\mathrm{Fe}(\mathrm{II})$. Rapid reoxidation of $\mathrm{Fe}(\mathrm{II})$ in oxic waters produces either amorphous precipitate ( $\mathrm{FeOOH})$ or soluble hydrolyzed $\mathrm{Fe}(\mathrm{III})$ that can be taken up by phytoplankton. The extent to which this photocycle results in measurable $\mathrm{Fe}(\mathrm{II})$ in bulk solution is uncertain. them more available to phytoplankton. This can be interpreted as a reductive photodissolution of the iron oxide, followed by immediate oxidative re-precipitation of $\mathrm{Fe}(\mathrm{II})$ on the oxide surface. The result is the formation of an amorphous iron-oxide surface whose solubility is markedly greater than that of aged and more crystalline solids and whose dissolution is faster. As expected, aged Fe oxides are less available to algae in cultures (Wells $e t$ al. 1983). An alternative interpretation of the beneficial effect of light on the bioavailability of $\mathrm{Fe}$ suspensions is that $\mathrm{Fe}(\mathrm{II})$ is released into solution by dissolution of the $\mathrm{Fe}$ (III) oxides. However, one should view with some circumspection reports of high-dissolved concentration of $\mathrm{Fe}(\mathrm{II})$ in seawater (O'Sullivan et al., 1991). The analytical techniques themselves are prone to reduce Fe(III) in the presence of natural organic material.

\section{Growth in Low Fe Medium}

The concentration of dissolved iron in some parts of the ocean has been measured at $\sim 0.05$ nM (Martin et al., 1989). Besides admiration for the analytical feat, such an extraordinarily low concentration summons up the question of how algae are able to survive in this environment. The rate of chemical binding of Fe by surface molecules is inherently limited by the rate at which water molecules can be removed from the hydration sphere of the dissolved iron species. This rate is fixed by the properties of Fe molecules and is beyond the power of the algae to modify to any significant extent. Thus, to grow at very low ambient Fe concentration, algae must either increase their number of uptake molecules or decrease their iron requirement.

\section{Maximize Uptake}

The maximum number of uptake molecules observed in phytoplankton corresponds to roughly one molecule per $10 \mathrm{~nm}^{2}$ of outer membrane (Hudson and Morel, 1990). This is a very high density of uptake molecules when one considers that, even with a molecular weight of only one thousand, they would then occupy roughly $5 \%$ of the available membrane area (which is already occupied by many other molecules, including transport proteins for major solutes). Such density likely nears the limit beyond which the lipid bilayers of the cell membrane lose their physical integrity. In a cell of $10-\mu \mathrm{m}$ diameter, this concentration of uptake molecules also results in an uptake rate that nears the limit of diffusion for dissolved iron species in solution. Thus, further increase in the concentration of uptake molecules in the membrane is probably impossible and is also useless in large algal cells because of the limit imposed by diffusion on the rate of physical transport to the cell surface (Fig. 3).

In a recent cruise to the equatorial Pacific Ocean (Price et al., 1991), we measured (upon 


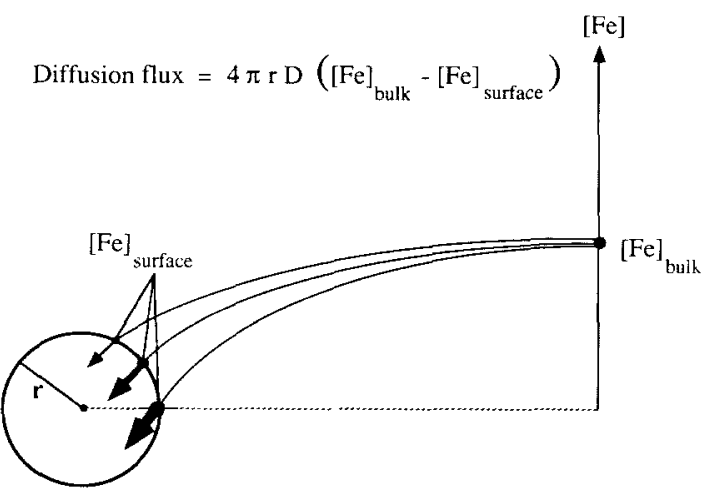

Fig. 3: The diffusion flux of Fe to a phytoplankton cell is proportional to the concentration gradient between the bulk solution $\left([\mathrm{Fe}]_{b u l k}\right)$ and the cell surface $\left([\mathrm{Fe}]_{\text {surtucc }}\right)$. This flux is thus increased by more efficient membrane transport that lowers the surface concentration $\left([\mathrm{Fe}]_{\text {surface }}\right)$. The maximum $\left(4 \pi r D[F e]_{\text {bulk }}\right)$ is obtained when the concentration of transport ligands is so high as to reduce the surface concentration to zero.

additions of high ${ }^{54} \mathrm{Fe}$ concentrations) extremely high maximum-Fe-uptake rates (Table 1). We deduce from these results that the concentration of Fe-transport molecules in the indigenous plankton populations approaches the maximum measured in laboratory cultures of $\mathrm{Fe}$-starved phytoplankton and is greatly in excess of that measured in either Fe-sufficient laboratory cultures or in coastal-water plankton. The clear implication is that the algae we sampled in the equatorial Pacific had maximized their Fe-uptake system because they were iron stressed if not iron limited.

\section{Minimize Requirements}

In our previous studies of iron uptake by common laboratory algae (Harrison and Morel, 1986), we reported a minimum cellular iron content for fast growth in the range of $\mathrm{Fe} / \mathrm{C} \approx 10 \mu \mathrm{mol} / \mathrm{mol}$, somewhat lower than the minimum theoretically necessary for the biochemical machinery of photosynthetic organisms utilizing nitrate. Yet these low experimental values now appear too high.

Our more recent results (based on actual carbon analysis instead of estimates from cell size) show an $\mathrm{Fe}: \mathrm{C}$ ratio down to $3 \mu \mathrm{mol} / \mathrm{mol}$. Other recent laboratory studies using oceanic clones (Sunda et al., 1991; Brand, 1991) have obtained an even lower minimum $\mathrm{Fe}$ content for algae dividing once a day: $\mathrm{Fe} / \mathrm{C} \approx 1-2 \mu \mathrm{mol} / \mathrm{mol}$. These results bring up the question of how these algae perform such a biochemical feat. Are they in fact more efficient than the theoretical calculations say they can be, or have they evolved replacements for iron-containing molecules and decreased further their iron requirements?

These new results also put into question the meaning of the relatively high $\mathrm{Fe}: \mathrm{C}$ ratios reported for phytoplankton in the North Pacific $(\sim 30$ $\mu \mathrm{mol} / \mathrm{mol}$ ) (Martin et al., 1989), which could indicate that the algae there are not Fe limited. In fact, these $\mathrm{Fe}: \mathrm{C}$ ratios are derived from the particulate $\mathrm{Fe}$ concentration corrected for its inorganic content by using a crustal $\mathrm{Al}: \mathrm{Fe}$ ratio of 3 . The applicability of this average ratio to a particular ocean environment is rather dubious, and no firm conclusion can be reached. We note that if one took the concentration of particulate iron leached by $25 \%$ acetic acid as the measure of biological iron (an equally dubious assumption), we calculate an Fe:C ratio in the North Pacific plankton of $\sim 1.5 \mu \mathrm{mol} / \mathrm{mol}$, which is in the range of new improved values for minimum algal iron content.

In view of the high iron cost involved in utilizing nitrate, one may hypothesize a direct link between iron limitation and high ambient nitrate concentrations in the regions of the oceans where nutrients are high and biomass is low (the North Pacific, the Equatorial Pacific, and the Southern Ocean). Indeed, several investigators have demonstrated that ammonium supplies a large fraction of the nitrogen to phytoplankton in these regions (Probyn and Painting, 1985; Wheeler and Kokkinakis, 1990; Dugdale et al.. 1991). [This is often described as a low f-ratio (Eppley and Peterson, 1979), the proportion of nitrate utilized by phytoplankton to their total inorganic nitrogen uptake.] We have found that upon Fe enrichment, shipboard cultures of algae indigenous to the Equatorial Pacific switch from utilizing primarily $\mathrm{NH}_{4}^{+}$to utilizing primarily $\mathrm{NO}_{3}^{-}$(Price et al., 1991). (The f-ratio goes from 0.2 to 0.8 over a few days.) No such switch is seen in the controls where no $\mathrm{Fe}$ is added. Thus, $\mathrm{Fe}$ enrichment appears uniquely to affect nitrate utilization by phyto-

Table 1

Concentration of Fe-transport molecules $\left(\mathrm{L}_{\mathrm{T}}\right)$ in equatorial Pacific plankton and in Fe-sufficient and Fe-deficient Thalassiosira weissflogii

\begin{tabular}{|c|c|}
\hline & {$\left[\mathrm{L}_{\mathrm{T}}\right]^{*}(\mu \mathrm{mol} / \mathrm{mol} \mathrm{C})$} \\
\hline \multicolumn{2}{|l|}{$T$. weissflogii } \\
\hline Fe-sufficient & 0.12 \\
\hline Fe-deficient & 3.0 \\
\hline \multicolumn{2}{|c|}{ Equatorial Pacific } \\
\hline $9^{\circ} \mathrm{N}, 140^{\circ} \mathrm{W}$ & 4.6 \\
\hline $3^{\circ} \mathrm{N}, 140^{\circ} \mathrm{W}$ & 1.2 \\
\hline \multicolumn{2}{|c|}{$\begin{array}{l}\text { *Calculated from } \mathrm{L}_{\mathrm{T}}=\rho_{\max } / \mathrm{k}_{\mathrm{in}} \text {, where } \mathrm{L}_{\mathrm{T}} \text { is } \\
\text { the number of Fe-transport molecules. } \rho_{\max } \text { is the } \\
\text { maximum Fe uptake rate, and } \mathrm{k}_{\mathrm{in}} \text { is the Fe inter- } \\
\text { nalization rate constant }\left(2 \times 10^{-3} \mathrm{sec}^{-1}\right) \text { (Hudson } \\
\text { and Morel, 1990). The maximum Fe-uptake rate } \\
\text { data used in these calculations are from Hudson } \\
\text { and Morel (1990) and Price et al. (1991). Equatorial } \\
\text { Pacific uptake rates were normalized to phyto- } \\
\text { plankton carbon, using a C/chl-a ratio of } 58 \mathrm{~g} / \mathrm{g} \\
\text { (Eppley et al., 1991). }\end{array}$} \\
\hline
\end{tabular}

... algae ... in the

equatorial Pacific had

maximized their

Fe-uptake system

because they were iron

stressed if not iron

limited. 
... oceanic regions

with high nutrient and

low biomass are

populated chiefly by

small algae . . . plankton in the Equatorial Pacific. We conclude that the low iron availability limits either the growth of nitrate users or the ability of all algae to utilize nitrate.

\section{Get Small}

An obvious way for phytoplankton to reduce their iron requirement is to become smaller. The requirement for any essential element must decrease roughly as the cube of the cell radius $\left(r^{3}\right)$, whereas the membrane area available for uptake molecules decreases as $r^{2}$ and the diffusion-limited rate as $r$. There is of course a limit to how small an organism can get (one estimate puts this minimum at $\sim 0.1 \mu \mathrm{m}^{3}$ for algae; Raven, 1986), but the presence of many small algal forms in oligotrophic waters is likely a reflection of the adaptation to low nutrient concentrations.

In particular it has been noted that the oceanic regions with high nutrient and low biomass are populated chiefly by small algae $<5 \mu \mathrm{m}$ in diameter(Booth, 1988; Chavez, 1989). It is tempting to interpret this fact as the result of iron limitation. Although we have not been able to confirm the result, others have reported an increase in the growth of large algae, particularly diatoms, upon Fe enrichment in shipboard cultures.

An Ecumenical Hypothesis (and Some Questions) Regarding Oceanic Regions With High Nutrients and Low Biomass

Despite the appearance of contradictory conclusions reached by various authors on the growth of algae in the North and Equatorial Pacific and the Southern Ocean, we believe that there is no disagreement on fact. All available data are surprisingly consistent and can be made to fit into a coherent hypothesis, reconciling the role of iron and grazing in controlling algal growth in these regions.

According to our view, the phytoplankton community in the oceanic regions of high nitrate and low chlorophyll are adapted to low iron. It is dominated by small, fast-growing phytoplankton that use chiefly $\mathrm{NH}_{4}^{+}$as a $\mathrm{N}$ source (low f-ratio). These phytoplankton are under some degree of Fe stress and incapable of using $\mathrm{NO}_{3}^{-}$or do so very slowly because of the additional Fe requirement for growth on oxidized $\mathrm{N}$. They are efficiently grazed by microzooplankton in a tightly coupled microbial loop; their biomass varies little seasonally and is controlled by grazers. Iron addition stimulates growth of the indigenous phytoplankton, including large cells that are initially rare. The resulting community utilizes $\mathrm{NO}_{3}^{-}$as its main $\mathrm{N}$ source for growth. Thus, low Fe concentration in these waters limits $\mathrm{NO}_{3}^{-}$utilization and new production (Price et al., 1991).

Certainly this, and any, version of the "iron hypothesis" has the merit of providing an explanation for the difference between oceanic regions of high nutrient and low biomass and others where the nutrients are all but exhausted. It is difficult to envision how a self-determined property of the local ecosystems such as grazing pressure could explain by itself these regional differences. However, a number of questions need to be answered before this hypothesis can be confirmed.

For example, we have not yet established or quantified the relationship between iron and nitrogen nutrition in marine-phytoplankton cultures, despite the clear biochemical basis for this relationship. We know even less, of course. of the iron physiology of the algal populations that seem to thrive in the North and Equatorial Pacific and in the Antarctic. A case in point is the degree to which $\mathrm{NH}_{4}^{+}$may inhibit $\mathrm{NO}_{3}^{-}$uptake by the indigenous phytoplankton community. A negative correlation between $\mathrm{NH}_{4}^{+}$and $\mathrm{NO}_{3}^{-}$uptake observed in the subarctic Pacific has been interpreted to demonstrate that $\mathrm{NH}_{4}^{+}$prevents $\mathrm{NO}_{3}^{-}$depletion (Wheeler and Kokkinakis, 1990). Nonetheless, in the equatorial Pacific the algae that take up $\mathrm{NO}_{3}^{-}$upon $\mathrm{Fe}$ enrichment do so in the presence of high $\mathrm{NH}_{4}^{+}$(Price et al., 1991). Are there effectively $\mathrm{NH}_{4}^{+}$and $\mathrm{NO}_{3}^{-}$specialists in these waters?

In any case, the unexpected behavior of some high-nutrient marine ecosystems provides us with an opportunity to unravel the complex relationship between trace elements, major nutrients, algae, and zooplankton. This clearly is a key to understanding how the ocean functions biologically.

\section{Acknowledgements}

Funding for this work was provided by grants from ONR (N 00014-90-J-1352) and NSF (OCE8917688).

\section{References}

Booth, B.C., 1988: Size classes and major taxonomic groups of phytoplankton at two locations in the subarctic Pacific Ocean in May and August. 1984. Mar. Biol., 97. 275286.

Brand, L.E., 1991: Minimum iron requirements of marine phytoplankton and implications for the biogeochemical control of new production. In: What Controls Phytoplankton Production in Nutrient-Rich Areas of the Open Sea?'S. Chisholm and F. Morel. eds., Limnol. Oceangr., 36

Chavez, F.P., 1989: Size distribution of phytoplankton in the central and eastern tropical Pacific. Global Biogeochem. Cycles, 3, 27-35.

Dugdale, R.C., F.P. Wilkerson, R.T. Barber and F.P. Chavez, 1991: Estimating new production in the equatorial Pacific Ocean at $150^{\circ}$ W. J. Geophy's. Res., 96.

Eppley, R.W. and B.J. Peterson, 1979: Particulate organic matter flux and planktonic new production in the deep ocean. Nature, 282, 677-680.

, F.P. Chavez and R.T. Barber. 1991: Standing stocks of particulate carbon and nitrogen in the equatorial $\mathrm{Pa}$ cific at $150^{\circ}$ W. J. Geophys. Res., 96.

Harrison, G.I. and F.M.M. Morel, 1986: Response of the marine diatom Thalassiosira weissflogii to iron stress. Limnol. Oceanogr., 31, 989-997.

Hudson, R.J.M. and F.M.M. Morel, 1990: Iron transport in marine phytoplankton: kinetics of cellular and medium 
coordination reactions. Limnol. Oceanogr., 35, 1002 1020.

Goldberg, E.D., 1952: Iron assimilation by marine diatoms. Biol. Bull., 102, 243-248.

Martin, J.H., 1991: Iron, Liebig's law, and the greenhouse. Oceanography, 4, 52-55.

and R.M. Gordon, 1988: Northeast Pacific iron distribution in relation to phytoplankton productivity. Deep-Sea Res., 35, 177-196.

R.M. Gordon, S. Fitzwater and W.W. Broenkow, 1989: VERTEX: Phytoplankton/iron studies in the Gulf of Alaska. Deep-Sea Res., 36, 649-680.

Miller, C.B., B.W. Frost, B. Booth, P.A. Wheeler, M.R. Landry and N. Welschmeyer, 1991: Ecological processes in the subarctic Pacific: iron-limitation cannot be the whole story. Oceanography, 4, 71-78.

Mitchell, B.G., E.A. Brody, O. Holm-Hansen, C. McClain, and J. Bishop, 1991: Light limitation of phytoplankton biomass and macronutrient utilization in the Southern Ocean. In: What Controls Phytoplankton Production in Nutrient-Rich Areas of the Open Sea? S. Chisholm and F. Morel, eds., Limnol. Oceangr., 36.

Morel, F.M.M., 1983: Principles of Aquatic Chemistry. John Wiley \& Sons, New York, 446 pp.

Neilands, J.B., 1981: Iron absorption and transport in microorganisms. Ann. Rev. Nutr., 1, 27-46.

O'Sullivan, D.W., A.K. Hanson, W.L. Miller and D.R. Kester, 1991: Measurement of Fe(II) in equatorial Pacific surface waters. In: What Controls Phytoplankton Production in Nutrient-Rich Areas of the Open Sea?'S. Chisholm and F. Morel, eds., Limnol. Oceangr., 36.

Price, N.M., L.F. Andersen and F.M.M. Morel, 1991: Iron and nitrogen nutrition of equatorial Pacific plankton. Deep-Sea Res., 38, 1361-1378.

Probyn, T.A. and S.J. Painting, 1985: Nitrogen uptake by size- fractionated phytoplankton populations in Antarctic surface waters. Limnol. Oceanogr., 30, 1327-1332.

Raven, J.A., 1986: Physiological consequences of extremely small size for autotrophic organisms in the sea. In: Photosynthetic Picoplankton, T. Platt and W.K.W. Li, eds., Can. Jour. Bull. Fish. Aquat. Sci., 214, 1-70.

1988: The iron and molybdenum use efficiencies of plant growth with different energy, carbon and nitrogen sources. New Phytologist, 109, 279-288.

Reid, R. and A. Butler, 1991: Isolation and characterization of novel siderophores from a marine Chromobacter: analysis of the molecular mechanism of iron acquisition. In: What Controls Phytoplankton Production in $\mathrm{Nu}$ trient-Rich Areas of the Open Sea? S. Chisholm and F. Morel, eds., Limnol. Oceangr., 36.

Rich, H.W. and F.M.M. Morel, 1990: Availability of well-defined iron colloids to the marine diatom Thalassiosira weissflogii. Limnol. Oceanogr., 35, 652-662.

Sunda, W.G., D. Swift and S.A. Huntsman, 1991: Iron content of oceanic marine phytoplankton. Nature, 351, 55-57.

Trick. C.G., R.J. Andersen, A. Gillam and P.J. Harrison, 1983: Prorocentrin: an extracellular siderophore produced by the marine dinoflagellate Prorocentrum minimum. Science, 219, 306-308.

Wells, M.L., N.S. Zorkin and A.G. Lewis, 1983: The role of colloid chemistry in providing a source of iron to phytoplankton. J. Mar. Res., 41, 731-746.

Wheeler, P.A. and S. Kokkinakis, 1990: Ammonium recycling limits nitrate use in the oceanic subarctic Pacific. Limnol. Oceanogr., 35, 1267-1278.

Wood, P.M., 1978: Interchangeable copper and iron proteins in algal photosynthesis. Eur. J. Biochem., 87, 9-19.

Zumft, W.G., and H. Spiller, 1971: Characterization of a flavodoxin from the green alga Chlorella. Biochem. Biophys. Res. Comm., 45, 112-118. 